\title{
PRE-PROGRAMMED FLIGHT PATH OF AIR-TO-GROUND MISSILE
}

\author{
M. Grzyb ${ }^{*}$, Z. Koruba ${ }^{* *}$
}

\begin{abstract}
The paper reports a control algorithm for air-to-ground missile that performs a pre-programmed flight along an ellipse section. The control system of the object flight is based on classical PD controllers. The efficiency of the system that guides the missile onto a ground target was analysed. The paper presents selected results of numerical simulations obtained using Matlab/Simulink package.
\end{abstract}

Keywords: missile, pre-programmed trajectory, guidance, control, dynamics

\section{Introduction}

The task of the control system in the air-to-ground missile is to guide the missile, with appropriate accuracy, to the ground target hitting range, or to ensure missile motion along a pre-programmed flight path. The paper discusses the means of implementation of the missile pre-programmed motion trajectory that has the form of an ellipse section. Then, the pre-programmed guidance is developed, aimed at destroying fixed ground targets (e.g. bunkers, bridges). The control system of the flying object is assumed to be autonomous. That means it is the onboard equipment that specifies the coordinates of the missile position in the vertical plane and provides control signals. Additionally, the onboard equipment does not receive any external information. The subject matter discussed in the paper is still a current issue. Research that deals with the development of autonomous control systems for flying objects is widely conducted. Such systems are used in unmanned flying vehicle (Sebbane, 2016), aircraft (Moore, 2012) or missiles (Koruba \& Nocoń, 2016). It often happens that combat mission task requires combined guidance, e.g. flight path along a pre-programmed trajectory to the region where the target is located, and homing at the final section of the path so that the target hitting precision could be ensured (Pharpatara et al.,2013).

\section{The control system of pre-programmed trajectory of the missile}

The objective of a combat mission, in which air-to-ground missiles are used, is to destroy mobile or fixed ground targets. The paper analyses autonomous control system for a missile guidance onto a ground target that was recognised beforehand, and the position of which is known.

The investigations concern air-to-ground missile, the dynamic motion equation of which was derived using Lagrange equations of second type (Koruba \& Osiecki, 1999). In order to derive missile motion equations, it was assumed that the mass, inertia moments, the missile centre of mass position do not change. Missile motion proceeds only in the vertical plane. Consequently, the missile motion equation can be expressed as follows:

$$
m \dot{V}_{m}=F_{p} \cos \alpha-m g \sin \gamma+\lambda_{x} V_{m}^{2}
$$

Research Assistant Marta Grzyb, MSc. Eng.: Department of Applied Computer Science and Armament Engineering, Faculty of Mechatronic and Mechanical Engineering, Kielce University of Technology, AlejaTysiącelcia Państwa Polskiego 7; 25314, Kielce; PL, mgrzyb@tu.kielce.pl

** Prof. dr habil. Zbigniew Koruba, Eng.: Department of Applied Computer Science and Armament Engineering, Faculty of Mechatronic and Mechanical Engineering, Kielce University of Technology, AlejaTysiącelcia Państwa Polskiego 7; 25-314, Kielce; PL, ksmzko@tu.kielce.pl 


$$
\begin{gathered}
m V_{m} \dot{\gamma}=F_{p} \sin \alpha-m g \cos \gamma+\lambda_{y} V_{m}^{2} \alpha+F_{q} \\
\ddot{\theta}=-D_{1} \frac{V_{m}^{2}}{l_{z}} \alpha-D_{2} V_{m} \dot{\alpha}-D_{3} V_{m} \dot{\theta}+\frac{F_{q} e}{J_{z}} \\
\lambda_{x}=\frac{c_{x a} \rho S_{x}}{2 m}, \lambda_{y}=\frac{c_{y a} \rho S_{y}}{2 m}, D_{1,2,3}=\frac{c_{i} l_{z}}{J_{z}}
\end{gathered}
$$

where: $\vec{V}_{m}$-missile velocity vector; $m$ - mass of the missile [kg]; $S_{x}$-cross-sectional area of the missile $\left[\mathrm{m}^{2}\right] ; S_{y}$-lifting area $\left[\mathrm{m}^{2}\right] ; g$ - acceleration of gravity $\left[\mathrm{m} / \mathrm{s}^{2}\right] ; l_{z}-$ length of the missile body; $c_{x a}, c_{y a}-$ coefficient of aerodynamic forces; $J_{z}$ - moments of inertia of the missile with respect to its transverse axis $\left[\mathrm{kgm}^{2}\right] ; \rho-$ air density $\left[\mathrm{kg} / \mathrm{m}^{3}\right] ; e$ - distance between control force and aerodynamic pressure centre; $\lambda_{x}, \lambda_{y}, D_{1,2,3}$ - relative aerodynamic coefficient of aerodynamic forces and moments $[1 / \mathrm{m}] ; c_{i}-$ coefficient of moments of aerodynamic forces; $F_{q}$ - missile flight control force [N]; $\gamma$ - flight-path angle in vertical plane [rad]; $\alpha$-attack angle [rad]; $\theta$-yaw angle of the missile [rad]; $F_{p}-$ thrust [N];

Very often, it is necessary to guide the missile to a certain point, at which it will be possible to recognize the target (Gapiński et al., 2014) and start the target homing process. It should be emphasized that the head proposed in this article can be used for various types of homing missile, including air-to-ground missiles. For that purpose, the first part of the trajectory is a pre-programmed flight. The shape of the flight path is essentially affected by missile purpose, velocity or permissible g-force acting on it.

With respect to the system under consideration, missile control involves the execution of the flight program. In the guidance process, it is not possible to correct the flight path. The equation of the preprogrammed path takes the shape of an ellipse section. The following parameters in the equation are known: the launch point coordinates $S\left(x_{s}, y_{s}\right)$, ground target coordinates $T\left(x_{t}, y_{t}\right)$ and the target attack angle $\gamma_{t}$. The equation that describes the programmed flight can be written in the following form:

$$
y_{p}(t)=a \sqrt{1-b \frac{x_{m}^{2}}{x_{t}^{2}}}-a \sqrt{1-b}, a=y_{s} \frac{y_{s}-x_{t} \operatorname{tg} \gamma_{t}}{2 y_{s}-x_{t} \operatorname{tg} \gamma_{t}}, b=1-\left(1-\frac{y_{s}}{a}\right)^{2}
$$

In the autonomous control system of the missile, the coordinates of the missile position and the control signals for control actuators are provided by the onboard equipment. In the flight, measurement devices of the guidance system take measurements of the current (actual) missile motion values. Then after processing, those values are compared in the predictor with the pre-programmed ones in the following form:

$$
e_{h}=y_{p}-y_{m} \text { and } e_{a}=\gamma_{p}-\gamma_{m}
$$

where: $y_{p}, y_{m}$ - programmed and actual position; $\gamma_{p}, \gamma_{m}$ - programmed and actual flight angle;

Based on the control deviations, control signals are generated in the missile autopilot. The missile control system was designed in such a way so that the errors were kept at the minimal level (close to zero values) during the guidance process (Skomra, 2005). The values of the control signals were adjusted using PD regulators, which were successfully used for other flying objects (Xu et al., 2015). Algorithm that specifies the value of the generated control signal can written as follows:

$$
F_{q}=k_{p h} e_{h}+k_{d h} \frac{d e_{h}}{d t}+k_{p a} e_{a}+k_{d a} \frac{d e_{a}}{d t}
$$

which constitutes a double PD controller. Generated control signals are transferred to the control actuator, which for the case of concern is the elevator. Control force thus created produces a change, or maintains the missile on the pre-set flight path, which ensures the missile control. Major advantages of the control system under consideration include virtually unlimited range, resistance to disturbances, and quite simple guidance apparatus. 


\section{Digital simulation results}

Numerical investigations were carried out using Matlab/Simulink package. Initial conditions for the autonomous flight of the missile guided onto a ground target take the following values: starting missile position: $x_{m 0}=0[\mathrm{~m}], y_{m 0}=3000[\mathrm{~m}]$; starting target position: $x_{t 0}=0[\mathrm{~m}], y_{t 0}=5000[\mathrm{~m}]$; angle of a missile launch: $\gamma_{m 0}=0$ [rad]; starting missile velocity: $V_{m 0}=100[\mathrm{~m} / \mathrm{s}] ; l_{z}=1.08[\mathrm{~m}] ; \mathrm{m}=11.8[\mathrm{~kg}] ; J_{z}=$ $1.1470\left[\mathrm{kgm}^{2}\right] ; \lambda_{x}=0.00074 ; \lambda_{y}=0.0067 ; D_{1}=0.0551 ; D_{2}=0.121 ; D_{3}=0.061$. The parameters of PD controllers were selected in the optimal way due to the minimal deviation between the programmed and actual value and were equal to (Gapiński \& Stefański, 2014): $k_{p h}=3.75 ; k_{d h}=0.3 ; k_{p a}=85 ; k_{d a}=0.12$;

Graphical representation of the results is shown in Figs 1-6.

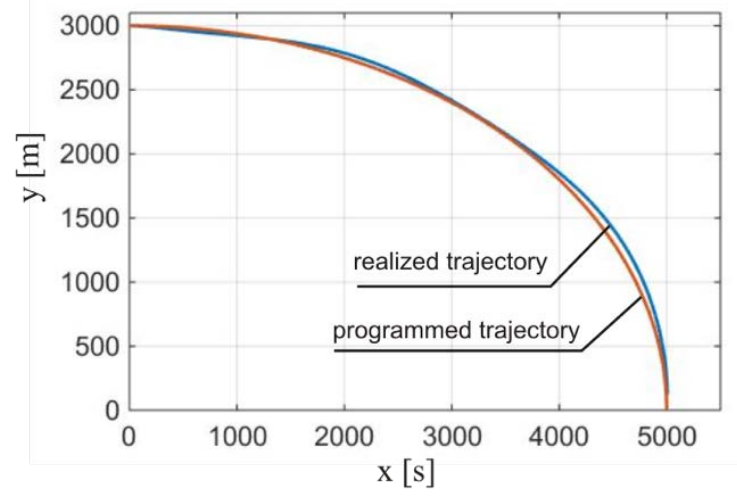

Fig. 1: The actual and programming flight paths of missile

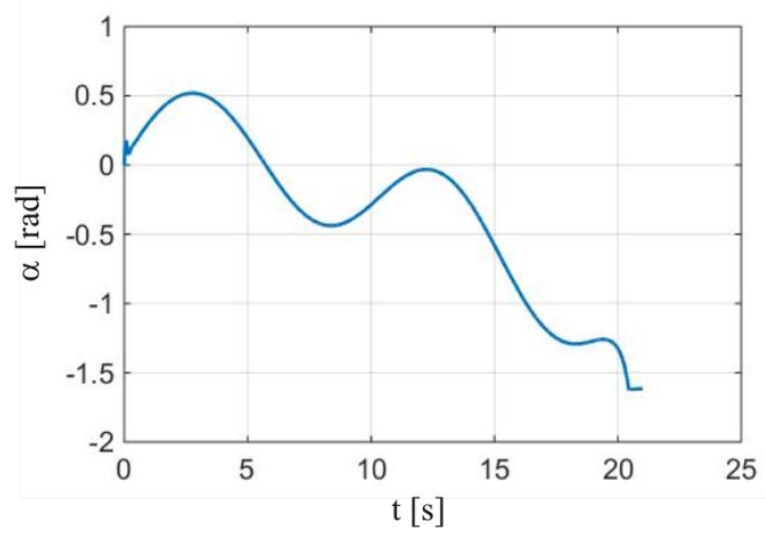

Fig. 3: The angle of attack realized during the missile flight

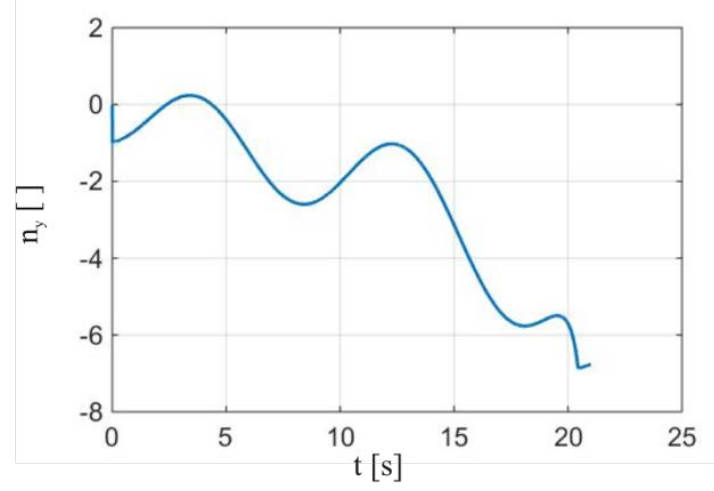

Fig. 5: Kinematic overloads

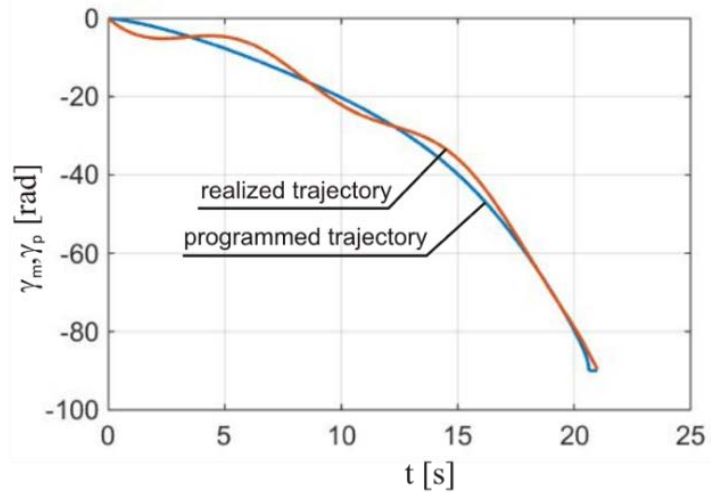

Fig. 2: The actual and programming angle of the missile flight

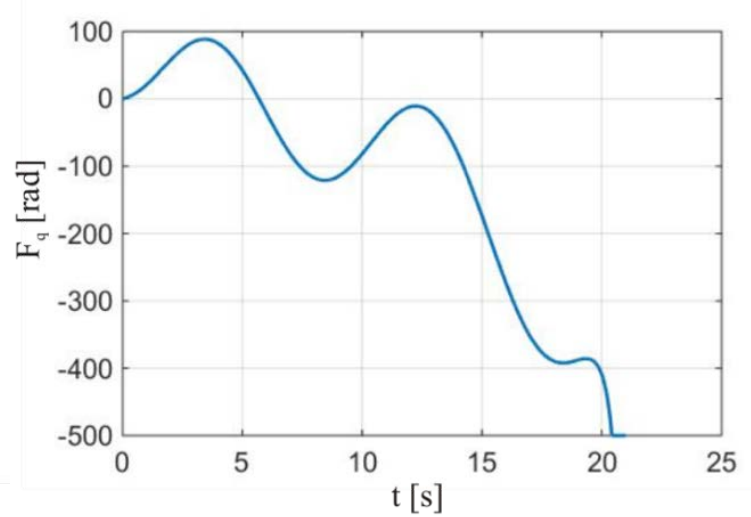

Fig. 4: The control forces during the missile flight

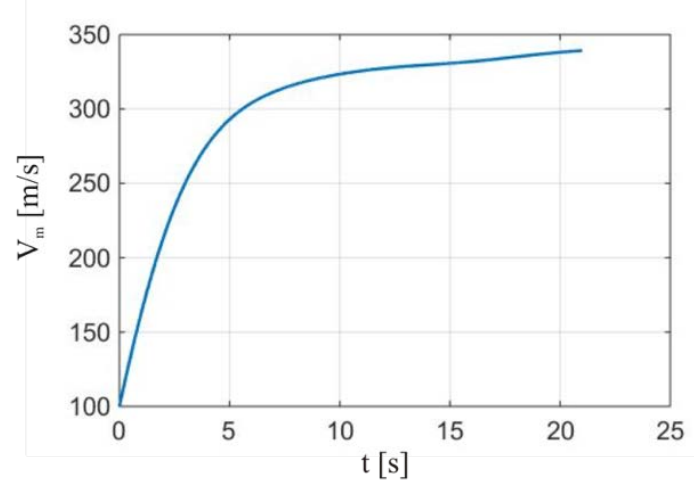

Fig. 6: Flight velocity of missile 
The obtained results show the effectiveness of the air-to-ground missile control algorithm. The source of the wave of the trajectory are the dynamic properties of the missile, including the high dynamics of the missile transition process. The value of the aerodynamic control force necessary to achieve the preprogrammed trajectory by the elevator does not exceed the permissible value of 500 [N]. The kinematic overloads acting on a missile during the flight have reached acceptable values. The angle of attack has reached only a few degrees and is feasible. In order to better implement the pre-programmed trajectory, an attempt will be made to optimally adjust the controller coefficients using, for example, the modified LQR method (Koruba \& Krzysztofik, 2017). The control system proposed allows fast and accurate hitting of the target (accuracy of hit was $4.85[\mathrm{~m}]$ ).

\section{Conclusions}

The study is an attempt to model missile flight along a pre-defined trajectory (a curve that has a form of an ellipse section) with the pre-set launch point, target point and attack. The efficiency of the autonomous missile control system in guidance along the pre-programmed flight path curve was analysed. Based on the numerical investigations, it is possible to state that the parameters under analysis, namely target hitting accuracy, g-loads acting on the missile in flight and also flight duration, take admissible values.

Further investigations will concern the pre-programmed flight for the case of missile spatial motion. It is also necessary to examine the impact of the selected guidance initial conditions including, e.g. initial drop angle, on the efficiency of the guidance system (Yao et al., 2016). Additionally, the effect of atmospheric conditions, such as turbulence, wind shear and wind gusts, on pre-programmed missile flight can be included in the analysis, the impact of which was previously studied for the guided bomb (Grzyb \& Stefański).

\section{References}

Gapiński, D., Krzysztofik, I. and Koruba Z. (2014) Analysis of the dynamics and control of the modified optical target seeker used in anti-aircraft rocket missiles. Journal of Theoretical and Applied Mechanics, 52, 3, pp. 629639.

Gapiński, D. and Stefański, K. (2014) A control of modified optical scanning and tracking head to detection and tracking air targets. Solid State Phenomena, 210, pp. 145-155.

Grzyb, M. and Stefański, K. (2017) Turbulence impact on the control of guided bomb unit. Engineering Mechanics 2017, Brno University of Technology, Brno, pp. 358-361.

Koruba, Z. and Krzysztofik, I. (2017) A control with the use of LQR modified method in the gyroscope system of target tracking. Engineering Mechanics 2017, Brno University of Technology, Brno, pp. 486-489.

Koruba, Z., Nocoń, Ł. (2016) Numerical analysis of the dynamics of automatically tracked anti-tank guided missile using polynomial functions, Journal of Theoretical and Applied Mechanics, 54, 1, pp. 13-25.

Koruba, Z. \& Osiecki, J.W. (1999) Constructions, Dynamics and Navigation of the Short Range Rocket Missile (in polish). 1st part, Academy Course Book, 348, Kielce University of Technology.

Moore R.J.D (2012) Vision Systems for Autonomous Aircraft Guidance. A thesis for the degree of Doctor of Philosophy at The University of Queensland.

Pharpatara P., Pepy R., Hérissé B., Bestaoui Y. (2013) Missile trajectory shaping using sampling-based path planning, in: Proc. 26th IEEE/RSJ International Conference on Intelligent Robots and Systems, Nov 2013, Tokyo, Japan, pp. 2533-2538.

Sebbane Y.B. (2016) Smart Autonomous Aircraft. Flight Control and Planning for UAV. CRC Press.

Xu Y., Wang Z., Gao B. (2015) Six-Degree_Freedom Digital Simulations for Missile Guidance and Control. Mathematical Problems in Engineering. Hindawi Publishing Corporation.

Yao Z., Yongzhi S., Xiangdong L. (2016) Trajectory reshaping based guidance with impact time and angle constraints. Chinese Journal of Aeronautics, 29, 4, pp. 984-994. 